\title{
Healthy Eating for Elders: Super Sandwiches ${ }^{1}$
}

Jennifer Hillan ${ }^{2}$
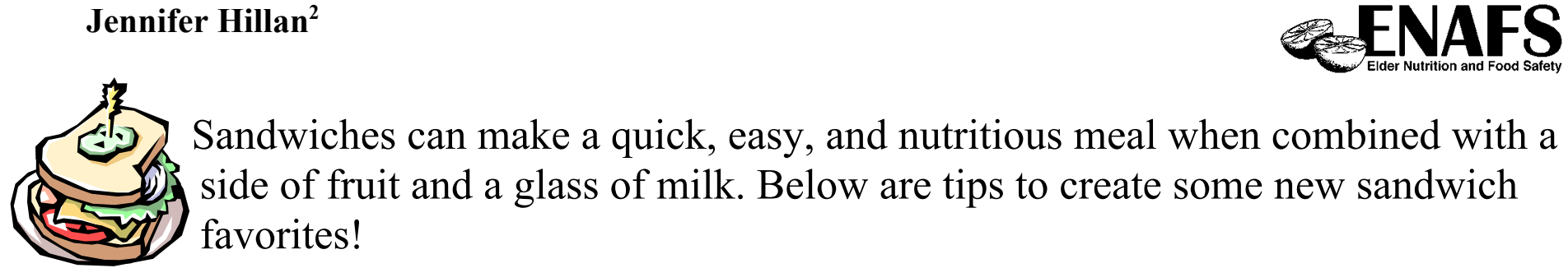

Sandwiches can make a quick, easy, and nutritious meal when combined with a side of fruit and a glass of milk. Below are tips to create some new sandwich favorites!

\section{BREADS}

Bread comes in many varieties. Experiment with sandwiches made on pita pockets, bagels, or tortillas!

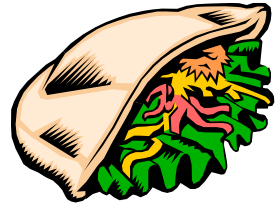

Choose whole-grain breads often. They provide energy, vitamins, minerals, and fiber. Try whole wheat, pumpernickel,

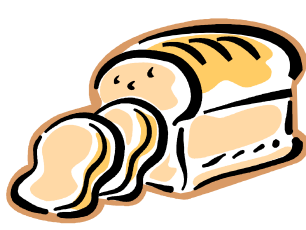
rye, or others made mainly with whole grain flour.

\section{FILLINGS}

For a lower fat dish, mix shredded tuna, turkey, or chicken with low-fat plain yogurt instead of mayonnaise.

Instead of peanut butter

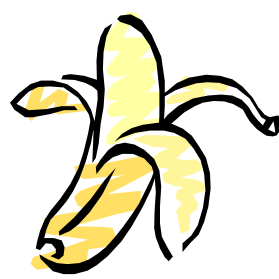
and jelly, how about peanut butter and banana? Add a little honey for a sweeter sandwich.
Try mashed canned beans or firm tofu flavored with chopped onion, parsley, garlic, pepper, or other

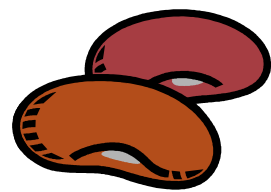
spices. Chickpeas, black beans, and kidney beans work well.

Go easy on spreads such as mayonnaise, margarine, butter, and cream cheese. They add calories and fat but few vitamins or minerals. Instead, try mustard, low-fat plain yogurt, or cottage cheese.

When buying deli meats, choose lean roast beef, ham, or turkey. Ask for meats without added salt.

\section{TOPPINGS}

Give your sandwich a

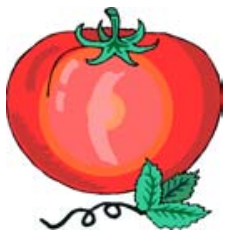
nutrition boost by adding vegetables or fruits. Try apples, pineapple, radishes, spinach, tomatoes, cabbage, cucumber, or grated carrots or zucchini.

1. This is document FCS 8699-ENG, one in a series of the Department of Family, Youth and Community Sciences, Florida Cooperative Extension Service, Institute of Food and Agricultural Sciences, University of Florida, Gainesville, FL 32611. Publication date: February 2005. This leaflet was developed with funding from the Florida Department of Elder Affairs in partnership with state, county, and local agencies. Please visit the EDIS website at http://edis.ifas.ufl.edu

2. Jennifer Hillan, MSH, RD, LD/N, former ENAFS nutrition educator/trainer, Department of Family, Youth and Community Sciences, University of Florida, Gainesville, FL 32611. Reviewed by Linda B. Bobroff, PhD, RD, LD/N, professor, and Leigh Ann Martin, MESS, former ENAFS project coordinator, University of Florida. 